Armament Research and Development Establishment : Dr. D. H. B!ack, C.M.G.

DR. D. H. BLACK, who has been appointed director of the Armament Research and Development Establishment of the Ministry of Supply, in succession to Mr. E. McEwen, was born in 1899 in New Zealand, where he received his early education, taking firstclass honours in physics at Canterbury. He came to Britain to work under the late Lord Rutherford in the Cavendish Laboratory, Cambridge, in 1923, gaining his Ph.D. in 1925. Dr. Black spent some fourteen years in industrial research with Standard Telephones and Cables, ultimately as head of the Valve Laboratory, before joining the Government service in September 1939, when he was appointed superintendent of the then Air Defence Experimental Establishment. In 1943, he was seconded to the Admiralty for special liaison duties in the United States, mainly concerned with new valve and electronic developments for radar and communications. He returned in 1945 as superintendent in charge of research at the now renamed Radar Research and Development Establishment, and in 1947 he moved to the headquarters of the Ministry of Supply, becoming director of electronics research and development in 1949. In 1953, Dr. Black was appointed head of the U.K. Ministry of Supply mission in Australia. During his three years in this post, the interests of the Ministry in Australia expanded considerably with the development of the guided weapon and atomic trials at Woomera and Maralinga. For his work in this post Dr. Black was appointed C.M.G. On returning to England in 1956, Dr. Black was appointed director-general of electronics research and development at the Ministry of Supply headquarters. Widely known in electronics and scientific circles, his appointment as head of the Armament Research and Development Establishment is indication of the increasing importance of electronics in all branches of armaments, as well as of his own personal and scientific strength.

\section{British Scientific Instrument Research Association :} Mr. R. J. Bracey

Mr. R. J. Bracey, head of the Optical Depart. ment of the British Scientific Instrument Research Association, will retire on July 31, after thirty-three years of service with the Association - and forty years of service to the optical industry. While still a boy, Bracey developed a deep interest in mathematics and a desire to apply his mathematical gifts to optical design, and after working for six years for a firm of shipbrokers and in a bank, he joined the firm of R. and J. Beck, the microscope makers. There he worked for the next seven years, in the shops and as a designer, until 1924, when Sir Herbert Jackson, then director of the British Scientific Instrument Research Association, invited Bracey to join the staff. Bracey's work during the next thirty-three years is reflected in the thirty-six research reports which bear his name or signature, twenty-four of them concerned specifically with optical design. Microscope objectives, including pioneering systems for ultra-violet microscopy ; optical systems for telescopes; illuminators; focometers for spectacle lenses ; systems of ray tracing; lens and mirror systems ; interferometers; collimators; the optics of clinical thermometers; the examination of bearing jewels-Bracey's field has been wide. The fi0.36 object-glass designed by Bracey for stellar spectro- scopy at the Mount Wilson Observatory is one of his most important designs. Bracey's long service to the industry will not end with his retirement. It may be, indeed, that one of his greatest services is still to come, because the monograph on optical design which he is now writing and will complete in retirement may well prove to be an outstanding contribution to the literature of the subject. His services as a consultant will still be available to the Research Association.

\section{Mount Wilson and Palomar Observatories: Dr. W. Baade}

Dr. WALter BAADE, who has been a member of the staff of the Mount Wilson and Palomar Observatories for twenty-seven years, is to retire. Dr. Baade, who was born at Schroettinghausen, in Germany, received his Ph.D. in 1919 at Göttingen and the same year was appointed to the staff of the Hamburg Observatory, where he remained until he received his appointment to the staff of Mount Wilson in 1931. Dr. Baade is noted for his discovery that two entirely different types of stars (Populations I and II) exist. This led to his recalibration of Cepheid variable stars in the Andromeda nebula, and his correction of the cosmicdistance scale. His work, which was reported at the International Astronomical Union meeting in September 1952 , indicated that all objects beyond the Milky Way are about twice as distant as had previously been supposed. He has also collaborated with Dr. Rudolph Minkowski in the identification of celestial radio sources with visual objects, and in the physical interpretation of the nature of these sources. In 1954, Dr. Baade was awarded the Gold Medal of the Royal Astronomical Society, "for his observational work on galactic and extragalactic objects".

\section{The Warren Spring Laboratory}

THE new Department of Scientific and Industrial Research Laboratory, now being built at Stevenage, will be called the Warren Spring Laboratory. The name is taken from a lane that used to run across the site on which the laboratory is being built. The Council for Scientific and Industrial Research has expressed the view that the Warren Spring Laboratory should be a versatile station, free to do work on any subject which becomes important for the nation and which cannot be fitted into the programme of another research body. It has already been decided that work will be carried out on air pollution; on the synthesis of oil and chemicals from carbon monoxide and hydrogen; and on mineral processing. The new station will, in addition, be free to take up any research requiring staff and facilities of the type that are being provided. Mr. S. H. Clarke, director of fire research, Department of Scientific and Industrial Research, has been appointed director of the Warren Spring Laboratory.

\section{International Inspection of Nuclear Power Plants}

A Question was asked in the House of Commons on July 10 as to whether Britain would make it a condition of supplying civilian nuclear power plants to Brazil, Germany, Spain and other countries that continuous inspection should be undertaken by the International Atomic Energy Agency. The Prime Minister replied, pointing out that the Agency has not yet worked out methods for implementing the inspection and other safeguard provisions in its governing statute. All that can be done is to specify 